\title{
Selective disruption of hypermnesia for pictures and words
}

\author{
DAVID G. PAYNE, JEFFREY S. ANASTASI, JASON M. BLACKWELL, and MICHAEL J. WENGER \\ State University of New York, Binghamton, New York
}

\begin{abstract}
In this study, we investigated the effects of various interpolated tasks on hypermnesia (improved recall across repeated tests) for pictures and words. In five experiments, subjects studied either pictures or words and then completed two free-recall tests, with varying activities interpolated between the tests. The tasks performed between tests were varied to test several hypotheses concerning the possible factor(s) responsible for disruption of the hypermnesic effect. In each experiment, hypermnesia was obtained in a control condition in which there was no interpolated task between tests. The remaining conditions showed that the effect of the interpolated tasks was related to the overlap of the cognitive processes involved in encoding the target items and performing the interpolated tasks. When pictures were used as the target items, no hypermnesia was obtained when subjects engaged in imaginal processing interpolated tasks, even when these tasks involved materials that were very distinct from the target items. When words were used as the target items, no hypermnesia was obtained when the interpolated tasks required verbal/linguistic processing, even when the items used in these tasks were auditorily presented. The results are discussed in terms of a strength-based model of associative memory.
\end{abstract}

In the past 20 years there have been many investigations of hypermnesia, which is an improvement in recall level associated with repeated testing (for reviews see Payne, 1987; Roediger \& Challis, 1989). Despite the impressive body of research and theorizing that has accumulated since the seminal work of Erdelyi and his colleagues (e.g., Erdelyi \& Becker, 1974; Erdelyi \& Kleinbard, 1978; Shapiro \& Erdelyi, 1974), no extant theory can account for all of the hypermnesia data. More importantly, one pattern of findings has eluded all theoretical explications: These findings are the facts that (1) hypermnesia is virtually always obtained with pictures, even under conditions in which no hypermnesia is found with words, and (2) when researchers have directly compared hypermnesia for pictures and words, the modal finding is that pictures produce a larger hypermnesic effect than do words (Payne, 1987). One reason that extant theories have failed to account for this pattern is that they have generally ignored the cognitive processes carried out following the study phase. One goal of the present research is to document that this variable plays a major role in determining performance levels across tests, and it therefore needs to be addressed in theoretical accounts of both hypermnesia and, more generally, memory across various retention intervals.

We begin by briefly reviewing the three main theoretical approaches to hypermnesia and the picture-word difference: The imagery hypothesis, proposed by Erdelyi and Becker (1974), the cumulative-recall-level hy-

Address correspondence to D. G. Payne, Department of Psychology, SUNY Binghamton, Binghamton, NY 13902-6000 (e-mail: dpayne@ bingvmb.bitnet). pothesis, initially proposed by Roediger, Payne, Gillespie, and Lean (1982) and subsequently modified by Payne (1986), and the search of associative memory (SAM) account, proposed by Raaijmakers and Shiffrin (1980). This review is intended to illustrate a common theme in these accounts and is therefore intentionally selective; for a more thorough review see Payne (1987).

The imagery hypothesis grew out of initial hypermnesia studies (e.g., Erdelyi \& Becker, 1974), which showed that although recall levels for pictures increased across tests, recall levels for words remained roughly constant. These observations led Erdelyi and Becker to propose that imaginal coding was a critical process underlying hypermnesia. Erdelyi and Becker couched their account of hypermnesia (and the picture-word difference) in terms of a dual-coding (e.g., Paivio, 1971) memory system and a generate-recognize model of recall (e.g., Kintsch, 1970). Erdelyi and Becker proposed two mechanisms to account for the hypermnesic effect they observed with pictures. First, each time a picture target item is successfully located in the memory system, there is "some sort of marking procedure.... With each success (resulting in recall) the candidate and its search paths are more extensively marked, allowing for faster and surer search-recognitions in subsequent recall attempts, leaving more and more time for additional searches of hitherto unlocated items" (Erdelyi \& Becker, 1974 , p. 167). The second mechanism was the highly accurate recognition of picture candidates retrieved from memory during the generate phase. This accurate recognition was presumed to be similar to the well-documented accuracy of picture-recognition memory (e.g., Shepard, 1967). With accurate picture recognition and sufficient 
marking of the retrieval paths, performance with pictorial materials would increase across tests. With words, however, the recognition process was presumed to be more error prone, thus reducing the efficiency of the retrieval path marking process.

Roediger et al. (1982) proposed an alternative account of hypermnesia that did not appeal to imaginal coding as a critical variable. According to their cumulativerecall-level hypothesis, hypermnesia is directly related to the difference between asymptotic cumulative recall (i.e., the total number of items that subjects could recover, given a specific set of study materials and encoding conditions) and the number of items recalled on Test 1 . According to this hypothesis, the reason that pictures produce a larger hypermnesic effect than words is that the asymptotic cumulative recall levels for pictures are typically higher than those for words.

Payne (1986) tested this hypothesis by presenting subjects with either pictures or words; recall level was manipulated by varying the number of list presentations or the item presentation rate. The results showed that even when the recall levels for words were equal to or greater than that observed with pictures, pictures still produced a larger hypermnesic effect. Pictures also produced a lower intertest forgetting rate than did words. On the basis of these data, Payne argued that, in addition to differences between performance levels on Test 1 and the asymptotic level of recall, changes in item accessibility that result from successful retrieval(s) also affect hypermnesia. Payne argued that retrieving pictures resulted in a greater increase in item accessibility than did recalling words, and that this was related to the differences observed in the number of items recalled on each test. Note that because there is no independent baseline measure of intertest forgetting, the difference in intertest forgetting between pictures and words could also be interpreted as indicating that recalling words decreased the accessibility of words more than did recalling the names of the pictured items.

Finally, Raaijmakers and Shiffrin (1980) accounted for hypermnesia through two mechanisms within their SAM model. First, the associative links between retrieved items and the retrieval cues used to recover the item are strengthened. These items can thus be recalled more quickly on subsequent tests, thereby allowing more time to retrieve previously unrecalled items. Second, Raaijmakers and Shiffrin postulated alternative retrieval routes: by changing the items in short-term memory that act as retrieval cues, the memory system can recover items that were not recalled with previous cues.

As this brief review illustrates, one common assumption of extant theoretical accounts of hypermnesia (e.g., Erdelyi \& Becker, 1974; Payne, 1986; Raaijmakers \& Shiffrin, 1980; Roediger et al., 1982) is that changes in item accessibility are viewed as a critical factor in producing hypermnesia. However, with the possible exception of the SAM interpretation, these theoretical statements have generally been quite vague regarding the mech- anisms underlying these changes (see Roediger \& Wheeler, 1993), and there has been little empirical work directed toward manipulating item accessibility across repeated tests. ${ }^{1}$ Thus, one goal of the present research was to provide insights into the mechanisms underlying item fluctuation rates (i.e., changes in item accessibility) across tests in order to determine how these processes might affect the magnitude of the hypermnesic effect and the picture-word difference in hypermnesia.

\section{Task Demands in Repeated Test Paradigms}

One possible clue to the picture-word difference comes from an analysis of the task demands in the picture and word conditions. Assume that subjects are given a single study phase followed by two recall tests. When Test 2 is given to subjects in the word condition, they have studied words, recalled words on Test 1 , and then received instructions for the second recall test. In contrast, when Test 2 is given to subjects in the picture condition, they have studied pictures, produced words on Test 1 (the names of the pictured items), and then received the Test 2 instructions. If the activities of recalling items and receiving instructions for the second test are more similar to the initial encoding activities in the word condition than to those in the picture condition, the retroactive interference on Test 2 in the word condition could be greater than that in the picture condition, as a function of the similarity of the processes employed in each phase of the experiment.

One possible way to test this hypothesis-that the more similar the cognitive processes employed at encoding and during the retention interval, the smaller the hypermnesic effect-is to orthogonally vary mode of item presentation (pictures vs. words) and test format (recall words vs. draw pictures). Dragone, Brown, Krane, and Krane (1980) performed such an experiment, in which subjects studied either pictures or words (the names of the pictured items). Within each item type group, half of the subjects recalled the names of the items, while the remaining subjects sketched a drawing of each of the items.

Although the design of Dragone et al.'s (1980) study seems appropriate for addressing the effect of the similarity of processes employed during study and test, several aspects of Dragone et al.'s methods make it difficult to draw firm conclusions regarding the impact of similar versus dissimilar formats for item presentation and recall testing. First, perhaps due to the difficulty of drawing pictures during the recall tests, each of the recall tests in Dragone et al.'s study was quite long ( $15 \mathrm{~min})$, and, as a consequence, performance may have been close to asymptote at the end of Test 1 . A second and perhaps more insurmountable problem is that it seems likely that it takes subjects longer to draw a picture of the target item than to write down the name of the target. If so, then across the two recall conditions there is a bias in favor of the word condition in terms of the amount of time subjects can devote to retrieving target items. The 
final problem with Dragone et al.'s study is that they reported only cumulative recall measures, not the net recall measure (i.e., the number of unique items recalled on each test), the measure typically employed to assess hypermnesia. Although it would be possible to replicate Dragone et al.'s study in order to obtain net recall data, the methodological problems described previously suggest that an alternative approach to testing the similarityof-processes notion would be preferable.

Shaw and Bekerian (1991) recently reported an intriguing study that illustrates a potentially useful approach for testing the similarity-of-processes hypothesis. Shaw and Bekerian had their subjects study word pairs under imaginal encoding instructions. The subjects then completed three recall tests with various activities performed between tests. The results showed that when the subjects were given interpolated tasks, such as thinking about the target items, reading a prose passage, or a perceptual-motor task involving tracing lines within the boundaries of a star shape, a significant hypermnesic effect was obtained. More importantly, when the interpolated task involved forming images in response to a set of words presented between tests, no hypermnesia was obtained. Shaw and Bekerian concluded that interpolated activities similar to the original encoding activities will decrease the effectiveness of the retrieval cues that subjects use to recall target items. When the subjects formed images of words' referents between tests, imaginal memory traces were established that rendered the retrieval cues used to recover the target items less effective. As a consequence, no hypermnesia was obtained in these conditions.

Although Shaw and Bekerian's (1991) study indicates that presenting interpolated activities between tests can help discern the processes that are critical for producing hypermnesia, there are a number of questions left unanswered by that study. First, given the robustness of the hypermnesic effect with pictures, it would be useful to know whether interfering effects, similar to those reported by Shaw and Bekerian, can be obtained when the target items are pictures. If so, it may be possible to systematically vary the nature of the stimulus materials as well as the interpolated tasks in order to determine the differences in the processing of pictures and words that are responsible for the different patterns of performance observed across tests.

A second question raised by Shaw and Bekerian's (1991) study is whether the engagement of cognitive processes that are similar to the encoding activities is responsible for the selective interference obtained in that study, or the fact that the interpolated tasks that interfered with the hypermnesic effect involved materials similar to the target items. In Shaw and Bekerian's study, each condition that failed to produce a hypermnesic effect involved presenting another list of words between tests. It is possible that these items, being similar to the target items as well as more recently experienced, effectively interfered with target item recall on Test 2 .
There is, however, evidence (e.g., Bekerian, 1986; Bird, 1976) that, although item similarity is an important determinant of interference, the cognitive operations engaged in processing the interpolated items also play a role. According to our similarity-of-processes hypothesis, the overlap in the cognitive processes determines whether an interpolated activity will produce interference.

The present experiments were designed to address these issues and provide several tests of the similarityof-processes hypothesis. Toward this end, we presented subjects with pictures or words to study and then administered two free-recall tests. In the control condition, the interval between tests was brief (1-2 $\mathrm{min})$, and during this interval the subjects were given materials and instructions for the second test. The remaining experimental conditions were designed to contrast several alternative interpretations for the disruption of the hypermnesic effect obtained by Shaw and Bekerian (1991). To derive predictions of how specific tasks interfere with the recall of pictures or words, we used Raaijmakers and Shiffrin's (1980) SAM theory as a starting point for considering the possible effect of the type of interpolated processing. Within SAM, successful recall of target items depends upon item-to-item and context-toitem associations formed during encoding. We believe that two consequences of performing an interpolated task between successive tests are to (1) alter the context within which the subsequent test is performed, and (2) add additional information to the memory system, which can affect the likelihood of successful recall of items (Gillund \& Shiffrin, 1984). For the present purposes, we assume that context is related to the type(s) of perceptual and cognitive processes that the individual has recently employed. We assumed that encoding words involves more verbal processing than does studying pictures and that studying pictures requires more imaginal processing than does studying words (Paivio, 1971; Wickens, 1980, 1984). We also assumed that the type of cognitive processes engaged in during encoding and/or the intertest interval could affect context and/or contextto-item associations. We predicted that interpolated activities that involve cognitive processes similar to those employed in encoding the to-be-remembered (TBR) items would decrease the magnitude of the observed hypermnesia by making the retrieval cues used on Test 2 less effective.

\section{EXPERIMENT 1}

In Experiment 1, subjects studied a list of common words and then completed two recall tests. To ensure that recall levels would be reasonably high (and hence increase the chances of obtaining a hypermnesic effect), we had the subjects perform a pleasantness rating task that has been shown to produce reasonably high recall levels (e.g., Einstein \& Hunt, 1980; Hunt \& Einstein, 1981). There were three conditions, which were determined by the type of activity in which the subjects were 
engaged between tests. The subjects in the control condition were the given second test shortly after the first test was completed. The subjects in the picture-naming condition performed an interpolated task that required processing of both spatial/imaginal and verbal representations. The subjects in this condition were presented with a series of pictures during the intertest interval and were required to write down the names of the pictured items. To further emphasize verbal processing, they were required to write the name of the item in reverse spelling order after initially naming the item. The subjects in the auditory word identification condition provided a test of the hypothesis that it is not the nature of the stimulus per se that affects recall levels on Test 2, but is the nature of the processes used to perform the interpolated task. The subjects in this condition were given auditory presentation of a short sentence, which was followed by a target word at a low level of speech intelligibility, and they attempted to identify the target word. If the physical similarity of the TBR items and the interpolated stimuli determine the magnitude of the hypermnesic effect, then this condition should produce a significant hypermnesic effect because the target and interpolated items differ in the modality of presentation. However, if the type of processing (verbal vs. imaginal) is important, then this condition should show a diminished hypermnesic effect for words relative to the control condition. Finally, this condition also allowed us to test the possibility that presenting any distracting task between tests will affect recall performance and hence decrease the likelihood of obtaining a hypermnesic effect.

\section{Method}

Subjects and Design. Seventy-six State University of New York at Binghamton introductory psychology students participated in partial fulfillment of a course requirement for laboratory or library research. A 3 (interpolated task: control, picture naming, auditory word identification) $\times 2$ (Tests 1 and 2) mixed-factorial design was used, with test manipulated within subjects. The subjects were randomly assigned, in groups of 6 or fewer, to one of the three interpolated task conditions. There were $25-26$ subjects assigned to each of the three conditions.

Materials. Forty-eight names of common objects, taken from the norms of Snodgrass and Vanderwart (1980), served as the study items. The picture-naming task employed 60 additional pictures from Snodgrass and Vanderwart; these items were selected in order to avoid obvious similarities/associations to the items in the target list. The auditory word identification task consisted of 60 items taken from the modified rhyme test (MRT; House, Williams, Hecker, \& Kryter, 1965).

Procedure. The subjects were told that they would be viewing 48 slides containing common English words and that their memory for the items would be tested. They were instructed to rate each item's pleasantness on a 6-point Likert-type scale $(1=e x$ tremely pleasant; $6=$ extremely unpleasant . Following these instructions, the study list was presented at a $5-\sec$ rate. After the list was presented, the subjects were given the instructions for the first 5-min recall test. They were warned that the test would be fairly long, and they were encouraged to use the entire test period to recall as many items as possible. They were also told that, after each minute of the test, they would be prompted to draw a line under the last word they had recalled. These instructions took approximately $2 \mathrm{~min}$ to read, and Test 1 began immediately after- ward. During Test 1 (and Test 2), after each minute passed, the experimenter said "Draw line Number 1," "Draw line Number 2," and so on.

At the end of Test 1 , the subjects in the picture-naming condition were told that they would next be viewing a series of slides containing pictures of common objects and that as each item was presented, they were to first write down the name of the pictured item and then write the name spelled in reverse order. The 60 picture slides were then presented at an 8-sec rate. The subjects in the auditory word identification condition were told that they would be presented with a series of tape-recorded sentences and that their task was to identify the word at the end of each sentence. All sentences were of the form "The next word is ...," followed by a target item (e.g., rang). ${ }^{2}$ The 60 sentences were then presented at an 8 -sec rate. After the picture-naming or auditory word identification tasks, the subjects were given the instructions for Test 2, which were followed immediately by the recall test. The subjects in the control condition received the Test 2 instructions immediately after Test 1 . All the subjects were explicitly encouraged to try to improve their recall scores on Test 2 and were instructed to recall as many items from the originally studied list as possible, regardless of whether the items had been recalled on the first test.

\section{Results}

The mean number of items recalled on Tests 1 and 2 in each condition are presented in Table 1. As expected, there was a hypermnesic effect observed in the control condition. In contrast, the picture-naming and auditory word identification conditions showed little improvement in net recall levels across tests.

A 3 (interpolated activity: control, picture naming, auditory word identification) $\times 2$ (Tests 1 and 2 ) mixedfactor analysis of variance (ANOVA) indicated that overall performance levels were equivalent in the three conditions $\left[F(2,73)=1.46, M S_{\mathrm{e}}=4.42, p=.24\right]$. (Unless otherwise stated, all results referred to as significant have $p<.05$.) More importantly, there was a significant hypermnesic effect $\left[F(1,73)=10.04, M S_{\mathrm{e}}=4.42\right]$. Al-

Table 1

Mean Net Recall Levels on Tests 1 and 2 and the Difference Between the Tests for Each Condition in Experiments 1-4

\begin{tabular}{|c|c|c|c|c|}
\hline Condition & Test 1 & Test 2 & Test 2 - Test 1 & $S E M$ \\
\hline \multicolumn{5}{|c|}{ Experiment 1 : Words } \\
\hline Control & 19.4 & 21.4 & $+2.0^{*}$ & .44 \\
\hline Picture-naming filler & 18.2 & 18.7 & +0.5 & .55 \\
\hline Auditory sentence filler & 18.8 & 19.6 & +0.8 & .75 \\
\hline \multicolumn{5}{|c|}{ Experiment 2: Pictures } \\
\hline Control & 20.1 & 21.9 & $+1.8^{*}$ & .52 \\
\hline Picture-naming filler & 19.3 & 18.7 & -0.6 & .61 \\
\hline Auditory sentence filler & 20.4 & 21.7 & $+1.3^{*}$ & .42 \\
\hline \multicolumn{5}{|c|}{ Experiment 3: Words } \\
\hline Control & 23.2 & 25.0 & $+1.8^{*}$ & .81 \\
\hline Word-fragment completion & 23.1 & 23.5 & +0.4 & .64 \\
\hline Picture filler & 21.7 & 20.1 & $-1.6^{*}$ & .67 \\
\hline Clock filler & 22.7 & 24.6 & $+1.9^{*}$ & .68 \\
\hline \multicolumn{5}{|c|}{ Experiment 4: Pictures } \\
\hline Control & 25.1 & 27.3 & $+2.2^{*}$ & .68 \\
\hline Word-fragment completion & 25.7 & 27.0 & $+1.3 \dagger$ & .82 \\
\hline Picture filler & 24.4 & 23.7 & -0.7 & .63 \\
\hline Clock filler & 26.0 & 25.0 & -1.0 & .73 \\
\hline
\end{tabular}

Note-SEM, standard error of the mean for the Test $2-$ Test 1 measure. ${ }^{*} p<.05 . \quad \dagger p<.07$. 
though the interpolated activity $\times$ test interaction did not reach significance $\left[F(2,73)=1.74, M S_{\mathrm{e}}=4.42, p=\right.$ .18 ], planned-comparison simple effects tests indicated that there was a significant hypermnesic effect in the nofiller-task control condition $\left[F(1,73)=11.32, M S_{\mathrm{e}}=\right.$ 4.42], but no hypermnesic effect in either the picturenaming $\left[F(1,73)=.65, M S_{\mathrm{e}}=4.42, p=.42\right]$ or auditory word identification conditions $\left[F(1,73)=1.81, M S_{\mathrm{e}}=\right.$ $4.42, p=.18]$.

\section{Discussion}

The results from the control condition demonstrated that the materials and study conditions were adequate to produce a hypermnesic effect. The data from the picture-naming condition are consistent with Shaw and Bekerian's (1991) finding that the hypermnesic effect for words can be removed by an interpolated task that requires processing verbal items. The results also showed that the hypermnesic effect was disrupted with verbal materials independently of whether these materials were generated by the subject (picture naming), provided by the experimenter (auditory word identification), or presented in a different modality (auditory word identification).

\section{EXPERIMENT 2}

In Experiment 2, we examined whether the results from Experiment 1 were due to the specific interpolated tasks employed, or whether the disruption was dependent upon the similarity between the encoding and cognitive processes required by the interpolated task. Experiment 2 was identical to Experiment 1, with the sole exception that the target items were pictures rather than words. If the disruption of the hypermnesic effect observed in Experiment 1 was due to generalized interference of the specific interpolated tasks, then we would expect to see the same pattern of data here-a significant hypermnesic effect in the control condition, but no effect the for picture-naming or auditory word identification conditions. According to the similarity-ofprocesses hypothesis, we should find a hypermnesic effect in the control and auditory word identification conditions, but not in the picture-naming condition, since only the latter requires imaginal processing.

\footnotetext{
Method

Subjects, Materials, Design, and Procedure. Seventy-nine subjects, drawn from the same population as that for Experiment 1, were randomly assigned in groups of 6 or fewer to the control, picture-naming, or auditory word identification conditions. There were $26-27$ subjects per condition. The subjects studied 48 pictures (taken from Snodgrass \& Vanderwart, 1980) corresponding to the items used in Experiment 1 and then completed two freerecall tests. The design was thus a 3 (interpolated activity: control, picture naming, auditory word identification) $\times 2$ (Tests 1 and 2) mixed factorial. The procedures were identical to those used in Experiment 1 , with the exception that the subjects were told that the target items were pictures of common objects.
}

\section{Results and Discussion}

As predicted by the similarity-of-processes hypothesis, there was a hypermnesic effect obtained in the control and auditory word identification conditions, but not in the picture-naming condition (see Table 1). A 3 (interpolated activity) $\times 2$ (test) ANOVA revealed a significant main effect of test $\left[F(1,76)=9.10, M S_{\mathrm{e}}=3.64\right]$ and a marginally significant main effect of interpolated activity $\left[F(2,76)=2.41, M S_{\mathrm{e}}=31.8, p<.10\right]$. There was also a significant filler task $\times$ test interaction $[F(2,76)$ $\left.=6.51, M S_{\mathrm{e}}=3.64\right]$. Simple effects tests revealed that the control and auditory word identification conditions both produced significant hypermnesic effects $[F(1,76)$ $=11.73, M S_{\mathrm{e}}=3.64$, and $F(1,76)=8.80, M S_{\mathrm{e}}=3.64$, respectively]. In contrast, the picture-naming condition did not yield a hypermnesic effect $[F(1,76)=1.47$, $\left.M S_{\mathrm{e}}=3.64\right]$ and actually showed a slight decrease in the number of items recalled on Test 2. This latter finding is especially important in light of the fact that these same TBR materials yielded a hypermnesic effect in the control and auditory word identification conditions.

Experiment 2 provides clear evidence for why there was no hypermnesic effect in the picture-naming and auditory word identification conditions in Experiment 1. In Experiment 2, only the picture-naming condition failed to yield a hypermnesic effect, suggesting that it is the similarity of the processes employed at encoding and during the between-test retention interval that is critical. Finally, note that the failure to obtain a hypermnesic effect for pictures in the picture-naming condition, if replicable, represents a very unusual finding in that the hypermnesic effect for pictures is extremely robust (see Payne, 1987).

\section{EXPERIMENT 3}

In Experiment 3, we used words as the study items and provided two additional interpolated tasks to examine several questions. To determine whether any imaginal processing task would disrupt the hypermnesic effect with words, we used two different imaginal processing tasks. The first was similar to the picture-naming task used in Experiment 1; subjects were required to name a pictured item and then produce associates of that item. This task was intended to require both imaginal and verbal processing.

In the second imaginal task, the subjects were provided with a time that was read as hour:minute (e.g., 6:20) and were required to form an image of an analog clock and determine the number of minutes between the minute and hour hands (Carlson, Khoo, Yaure, \& Schneider, 1990). Since this task does not require retrieving or accessing the meaning of an item (as was the case with the picture-naming task), we predicted that it would not inhibit the hypermnesic effect for words. In addition, since this task involves auditory presentation, we can ask whether the modality of presentation or the 
processing demands of the task was responsible for the disruption of the hypermnesic effect observed in the auditory word identification condition in Experiment 1.

A second question addressed in Experiment 3 was whether the hypermnesic effect could be disrupted by using a verbal task other than the auditory word identification task. Toward this end, we used a word-fragment completion task. On the basis on the similarity-of-processes hypothesis, we predicted that, because this is an inherently verbal task, it would interfere with hypermnesia for words.

\section{Method}

Subjects and Design. Seventy-two subjects, drawn from the same population as that for Experiment 1, were randomly assigned in groups of 6 or fewer to one of the four between-subjects experimental conditions $(n=18)$. Each subject completed two tests, and thus the experiment employed a 4 (interpolated activity: control, picture filler, clock filler, word-fragment completion) $\times 2$ (Tests 1 and 2) mixed-factorial design.

Materials and Procedure. The TBR materials were the 48 words used in Experiment 1. The picture filler task was similar to the one used in Experiment 1. The subjects were presented with pictures of common objects and were asked to name the pictured item and then write down as many words as they could think of that were associated with the item. The clock filler task was taken from Carlson et al. (1990); it consisted of a list of times read by the experimenter as hour:minute. In the word-fragment completion filler task, the subjects were given word fragments taken from Tulving, Schacter, and Stark (1982) and were told to add letters to complete the words.

The study and Test 1 procedures were exactly the same as those used in Experiment 1. The subjects in the control condition received instructions and completed Test 2 immediately after Test 1. The subjects in the picture-naming condition were required to write down the name of the object and then generate associates to the presented item; pictures were presented at a $7-\mathrm{sec}$ rate. The subjects in the clock filler condition were told that they would be read a list of times, and that their task was to imagine an analog clock and determine the number of minutes between the minute hand and the hour hand. They were told to always use the shortest distance between the hands (i.e., the largest response should be 30 ); times were read at a 7-sec rate. The subjects in the wordfragment completion condition were given a sheet containing 104 word fragments and were told to complete each word. Each of the filler tasks lasted $8 \mathrm{~min}$. Immediately after these filler tasks, the subjects were given brief instructions and then completed Test 2 .

\section{Results and Discussion}

The net recall data from the four conditions are presented in Table 1. A 4 (interpolated activity) $\times 2$ (test) ANOVA revealed a marginal main effect of test $\left[F(1,68)=3.40, M S_{\mathrm{e}}=4.39, p<.07\right]$ and no main effect of interpolated activity $\left[F(3,68)=1.72, M S_{\mathrm{e}}=42.26, p=\right.$ .17]. There was, however, a significant interpolated activity $\times$ test interaction $\left[F(3,68)=5.34, M S_{\mathrm{e}}=4.39\right]$, indicating that the magnitude of the hypermnesic effect varied as a function of the interpolated activity. These results are consistent with the similarity-of-processes hypothesis. Simple effects tests showed that the control and clock filler conditions produced a significant hypermnesic effect $\left[F(1,68)=6.44, M S_{\mathrm{e}}=4.39\right.$, and $F(1,68)=7.31, M S_{\mathrm{e}}=4.39$, respectively]. The picture filler condition showed a significant decrease in net recall from Test 1 to Test $2[F(1,68)=4.96, M S e=4.39]$, and the word-fragment completion filler condition showed no change in performance across tests $[F(1,68)=0.38$, $\left.M S_{\mathrm{e}}=4.39, p=.54\right]$. A comparison of the results from the picture filler conditions in Experiments 1 and 2 indicates that requiring subjects to produce associates of the presented items was more disruptive to the hypermnesic effect than was the relatively shallow reverseorder spelling task in Experiment 1.

There were two other interesting findings in the clock filler condition. First, although the clock filler and picture filler tasks both required imaginal processing, the clock filler task did not require the subjects to utilize verbal/linguistic labels for discrete stimuli during the filler period. The fact that the clock filler condition produced a hypermnesic effect fails to support Shaw and Bekerian's (1991) hypothesis that any intertest activity that uses imaginal processes will disrupt the hypermnesic effect.

Second, note that the clock filler task involved auditory presentation of interpolated materials, as did the auditory word identification task used in Experiment 1. The fact that the clock filler task produced a hypermnesic effect in Experiment 3 indicates that it is not simply the presentation of an auditory task that produced the failure to obtain a hypermnesic effect with the auditory word identification task in Experiment 1.

\section{EXPERIMENT 4}

Experiment 4 was identical to Experiment 3, with the exception that the TBR items were pictures rather than words. On the basis of the similarity-of-processes hypothesis, we predicted a hypermnesic effect for the nofiller-task and the word-fragment completion conditions (since they did not involve imaginal processing), but no hypermnesia for either the picture filler or the clock filler conditions (since they both utilized imaginal processing).

\section{Method}

Subjects, Design, Materials, and Procedure. Ninety-two subjects, drawn from the same population as that in Experiment 1, were randomly assigned in groups of 6 or fewer to one of the four between-subjects experimental conditions $(n=23)$. The design of the experiment was a 4 (interpolated activity: no filler task, picture filler, clock filler, word-fragment completion) $\times 2$ (Tests 1 and 2) mixed factorial. The TBR materials were the 48 pictures used in Experiment 1. The procedures used were the same as those used in Experiment 3, except the subjects studied pictures rather than words.

\section{Results and Discussion}

As predicted, hypermnesia was observed in the control and word-fragment completion conditions, but there was no hypermnesia in the picture filler and clock filler conditions. A 4 (interpolated activity) $\times 2$ (test) ANOVA revealed no main effect of interpolated activity $[F(3,88)$ $\left.=1.00, M S_{\mathrm{e}}=49.26\right]$ or test $\left[F(1,88)=1.54, M S_{\mathrm{e}}=\right.$ 
5.92]. There was, however, a significant interpolated activity $\times$ test interaction $\left[F(3,88)=4.65, M S_{\mathrm{e}}=5.92\right]$. Simple effects tests showed that although the control condition produced a significant hypermnesic effect $\left[F(1,88)=9.18, M S_{\mathrm{e}}=5.92\right]$, and the word-fragment completion filler condition showed a marginal hypermnesic effect $\left[F(1,88)=3.31, M S_{\mathrm{e}}=5.92, p<.07\right]$, there was no hypermnesic effect for either the picture or the clock filler conditions $\left[F(1,88)=.72, M S_{\mathrm{e}}=5.92\right.$, and $F(1,88)=2.30, M S_{\mathrm{e}}=5.92$, respectively], both of which showed a small but nonsignificant decrease in net recall from Test 1 to Test 2 .

\section{EXPERIMENT 5}

Experiment 5 was designed to test an alternative account of results of Experiments 1-4. Given that the words used in Experiments 1 and 3 were high-imagery words and the subjects were not given specific encoding instructions, it is possible to argue that the subjects encoded these items in an imaginal format (cf. Paivio, 1971). If so, then the results of Experiments 1-4 would actually provide evidence against the similarity-ofprocesses hypothesis: If imaginal encoding processes were used in both the picture and the word conditions, yet yielded different patterns of results, this would suggest that something other than encoding processes (e.g., material presentation format) was responsible for the differences obtained across experiments.

One way to address this issue would be to compare performance in two groups of subjects-one that studies pictures and another that studies words using a specific encoding strategy (e.g., form an image of each item's referent). A major problem with this approach is that pictures typically produce higher levels of recall than do words, even when subjects have been instructed to use imagery mnemonics with the words (e.g., Erdelyi, Finkelstein, Herrell, Miller, \& Thomas, 1976). Furthermore, the magnitude of the hypermnesic effect is generally related to recall level, and, despite the fact that the encoding task used in Experiments 1 and 3 (pleasantness rating) was intended to raise recall levels, there was nonetheless a consistent recall advantage for pictures over words.

To address this issue, we used high-imagery words as the target items in Experiment 5 and instructed the subjects to study the items either by forming an image of the target item or by thinking about the meaning of the target item. On the basis on the similarity-of-processes hypothesis, we predicted that we would obtain a larger hypermnesic effect when the encoding and interpolated tasks required different processes (e.g., imaginal encoding instructions and a verbal interpolated task) than when they required similar processes. We thus predicted a three-way interaction of encoding condition (verbal vs. imaginal), interpolated task (verbal vs. imaginal), and test $(1,2)$. Note that if the subjects in Experiments 1 and 3 had spontaneously employed imaginal encoding of the word targets, then the results from the imaginal encoding condition in Experiment 5 should parallel those found in Experiments 1 and 3-a larger hypermnesic effect with the verbal interpolated task than with the imaginal task.

\section{Method}

Subjects and Design. Eighty-nine subjects were drawn from the same population as that in the previous experiment and were randomly assigned in groups of 6 or fewer to one of the four betweensubjects experimental conditions $(n=21-24)$. The design of the experiment was thus a 2 (encoding condition: imaginal, verbal elaboration) $\times 2$ (interpolated activity: clock filler, sentence comprehension) $\times 2$ (Tests 1 and 2 ) mixed factorial.

Materials, Procedure, and Apparatus. The TBR items were the names of 42 items from Snodgrass and Vanderwart (1980). The clock filler task was identical to the one used in Experiment 3, with the exception that the times were visually displayed on a screen at the front of the room. All the times remained on the screen for $5 \mathrm{sec}$, with a $1-\mathrm{sec}$ blank screen between items. The sentence comprehension task involved 80 short sentences, with each missing a single word. Each sentence was presented for $2 \mathrm{sec}$ and was followed by a 1-sec blank screen and then a target word that was presented for $2 \mathrm{sec}$. The subjects were required to decide whether or not the sentence made sense when the target word was inserted. There was a $1-\mathrm{sec}$ pause following each target word, and then the next sentence frame was presented. In half of the sentences the target word made sense, and for the remaining sentences the target did not make sense. Presentation of the study list and interpolated task was controlled by an Apple Macintosh LC II computer that was interfaced with an InFocus 1600 LC LCD projection system and an overhead projector.

The subjects in both encoding conditions were told that they would be presented with a list of English words and that their memory for these items would be tested. The subjects in the imaginal encoding condition were told that, as each word was presented, they were to envision the word's referent. They were also instructed to concentrate on the image and make it as clear and as vivid as possible. The subjects in the verbal elaboration condition were told to concentrate on the meaning of each item and to try to think of associates of the item. After these instructions, the TBR items were presented at a $5-\mathrm{sec}$ rate

After the study list was presented, the subjects spent 2 min recalling the names of the presidents of the United States and were then given the instructions for Test 1 . At the end of Test 1 , they received instructions for the appropriate interpolated task. The clock filler instructions were the same as those described in Experiment 3 . The subjects in the sentence comprehension condition were told that they would be presented with sentence frames followed by target words and that their task was to decide whether the target word made sense in the sentence frame and to indicate their decision by writing "Y" or "N" on their response sheets. Both filler tasks lasted $8 \mathrm{~min}$, and at the conclusion of these tasks the subjects were given the instructions for Test 2. Both free-recall tests lasted $5 \mathrm{~min}$.

\section{Results and Discussion}

The mean net recall levels for Tests 1 and 2 for the four experimental conditions are presented in Figure 1. As predicted by the similarity-of-processes hypothesis, the change in recall levels from Test 1 to Test 2 varied as a function of the encoding condition as well as the interpolated task. For the imaginal encoding conditions, there was a hypermnesic effect for the sentence comprehension condition as well as a decrease in recall on 

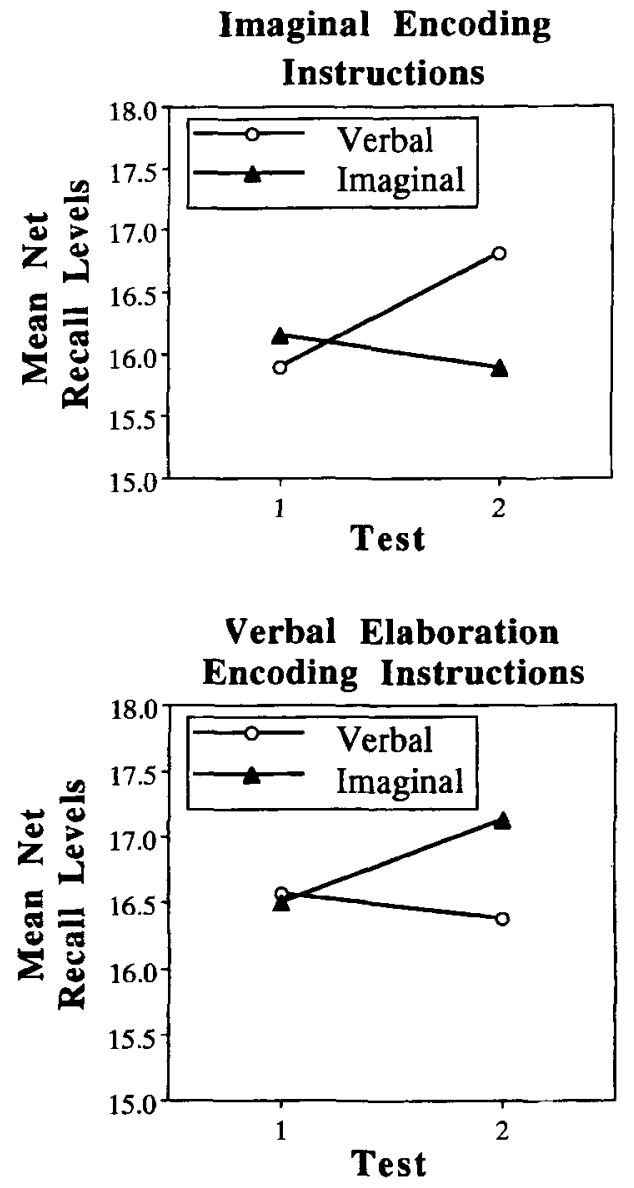

Figure 1. Mean number of items recalled on Tests 1 and 2 for the imaginal encoding condition (upper panel) and the verbal elaboration condition (lower panel) in Experiment 5.

Test 2 in the clock filler condition. Note that this result is exactly the opposite of that found in Experiments 1 and 3 , where the imaginal interpolated task conditions produced a hypermnesic effect but the verbal interpolated task conditions did not. If the subjects in Experiments 1 and 3 had spontaneously encoded the words in an imaginal format, we would expect the results of the imaginal encoding condition in Experiment 5 to be the same as those in Experiments 1 and 3. Also consistent with the similarity-of-processes hypothesis is the fact that the verbal elaboration groups produced a hypermnesic effect in the clock filler condition, but showed a slight decrease in performance in the sentence comprehension condition.

The net recall data were analyzed with a 2 (encoding condition: imaginal, verbal elaboration) $\times 2$ (interpolated activity: clock filler, sentence comprehension) $\times$ 2 (Tests 1 and 2) mixed-factor ANOVA. There were no significant main effects, and none of the two-way interactions approached significance (all $p s>.25$ ). However, as predicted, there was a significant encoding condition $\times$ interpolated activity $\times$ test interaction $[F(1,85)=$ $\left.5.75, M S_{\mathrm{e}}=2.09\right]$.
This three-way interaction was probed further with two separate analyses - one using the data from the two conditions in which the encoding instructions and interpolated activity required similar processes, and a second using the data from the two conditions in which the encoding instructions and the interpolated activity required dissimilar processes. A 2 (condition: verbal encoding/sentence comprehension, imaginal encoding/ clock filler) $\times 2$ (Tests 1 and 2) ANOVA that compared performance across tests in the conditions in which there were similar processes at encoding and during the intertest interval revealed no main effects or interactions (all $p$ s > 38). In contrast, a 2 (condition: verbal encoding/clock filler, imaginal encoding/sentence comprehension) $\times 2$ (Tests 1 and 2) ANOVA that compared performance in the two conditions with dissimilar processes at encoding and during the intertest interval revealed a significant main effect for test $[F(1,43)=5.65$, $\left.M S_{\mathrm{e}}=2.32\right]$. There were no other significant effects.

\section{GENERAL DISCUSSION}

The net recall results from the present experiments yielded several findings that may be summarized quite simply: The disruption of the hypermnesic effect depended upon the similarity of the cognitive processes required by the initial encoding task and the subsequent interpolated tasks. First, using words and no special encoding instructions, interpolated tasks that involved verbal processing disrupted the hypermnesic effect; with pictures, however, only interpolated tasks that required processing spatial/imaginal information disrupted the hypermnesic effect. Second, encoding instructions also played a major role. When the subjects studied words following imaginal coding instructions, the data mimicked that obtained with pictures. In contrast, instructing the subjects to think about the meaning of the words led to results that were similar to those of the word conditions, when no special encoding instructions were given.

These results replicate and extend the findings of Shaw and Bekerian (1991) and provide answers to several questions raised by that study. First, Experiments 2 and 4 demonstrated that the disruption of the hypermnesic effect is not limited to words, but can be obtained with pictures as well. Second, our experiments demonstrated that the disruption of the hypermnesic effect is not dependent upon presenting items similar to the target items during the intertest interval. Recall that Shaw and Bekerian found disruption of the hypermnesic effect with interpolated tasks that used both materials (words) and cognitive operations (imaginal coding) that were similar to those of the study conditions. Our experiments included a number of conditions in which the interpolated task involved materials that were quite dissimilar from the target items, and yet we still disrupted the hypermnesic effect.

There are several points to note concerning the results obtained with our interpolated tasks. First, the materials 
presented during the intertest interval differed in several ways from the items presented during study. These conditions employed auditory presentations (auditory word identification, clock filler conditions) rather than visual presentations, letter strings rather than intact words (word-fragment completion), and descriptions of times (clock filler). Thus, independently of the mode of presentation, the surface features of the stimuli used in the interpolated task, and whether the items to be used in the interpolated task were provided by the experimenter or generated by the subject, we still observed selective interference: The effects depended upon the similarity of processing involved in performing the interpolated tasks. This conclusion is based on the different pattern of results obtained with pictures and words in Experiments 1-4 and on the differential effects obtained with words studied under imaginal encoding and verbal elaboration instructions in Experiment 5. Taken together, the results from Shaw and Bekerian (1991) and those from the present study indicate that the hypermnesic effect can be systematically manipulated by varying the demands of the interpolated task.

We believe that one (but clearly not the only) potent variable affecting the picture-word difference in hypermnesia is the similarity of the processes involved in encoding and recalling pictures and words. In light of the present results, we would argue that recalling words has a more disruptive effect on the subsequent retrieval of words than does recalling pictures. The basic notion here is that recalling words is more similar to the initial encoding of words than recalling the names of pictures is to the encoding of pictures. Note that the similarity-ofprocesses view can also account for the finding that words that are studied by using imaginal encoding processes show a hypermnesic effect that is comparable to that obtained with pictures (Erdelyi et al., 1976).

An alternative account of the picture-word difference in hypermnesia was suggested by Payne (1986). Recall that when Payne equated the recall levels for pictures and words, he found that pictures produced a larger hypermnesic effect. Payne attributed this difference to pictures' producing lower rates of intertest forgetting than words, due to inherent differences between retrieving words and pictures (see Payne, 1986, p. 28, for a discussion of these differences).

The main difficulty with attempting to decide whether the learning-during-testing explanation proposed by Payne (1986) or the similarity-of-processes view proposed here provides a better account of the picture-word difference is that there is no baseline from which to know whether (1) performance was boosted more with pictures than with words (as assumed by Payne, 1986) or (2) performance was hindered more as a consequence of recalling words rather than pictures (as suggested by the similarity-of-processes hypothesis). Furthermore, it is quite likely that the act of recalling items has both positive and negative consequences for subsequent performance. Additional systematic research will be needed before these effects can be fully understood. One poten- tially useful approach for investigating the effects of recalling items is to use cued-recall tests, in which the researcher has greater control over retrieval processes than is typically the case with free recall. Payne, Hembrooke, and Anastasi (1993) have recently demonstrated that hypermnesia can be obtained with cued-recall tests. By varying the nature of the cues used to probe memory, it may be possible to elucidate in more detail the positive and negative consequences of recalling items. Data from studies such as this should also help in our efforts to develop theoretical accounts of performance across repeated tests. It is also quite likely that such investigations would have implications for memory in real-world settings, since most of what people learn in the real world is not intended for use on a single event/test, but is intended for repeated use.

\section{REFERENCES}

BEKERIAN, D. A. (1986). Similarity of internal learning environments and retroactive inhibition. American Journal of Psychology, 99, 4555.

BIRD, C. P. (1976). On the role of processing requirement in short-term memory. Journal of Experimental Psychology: Human Learning \& Memory, 2, 234-243.

Carlson, R. A., Khoo, B. H., Yaure, R. G., \& Schneider, W. (1990). Acquisition of a problem-solving skill: Levels of organization and use of working memory. Journal of Experimental Psychology: General, 119, 193-214.

Dragone, G. A., Brown, M., Krane, A. R., \& Krane, R. V. (1980). Hypermnesia for pictures and for words: The role of recall modality (pictures vs. words). Bulletin of the Psychonomic Society, 16, 258-260.

EINSTEIN, G. O., \& HuNT, R. R. (1980). Levels of processing and organization: Additive effects of individual item and relational processing. Journal of Experimental Psychology: Human Learning \& Memory, 6, 268-294.

ERdelyi, M. H., \& BECKER, J. (1974). Hypermnesia for pictures: Incremental memory for pictures but not words in multiple recall trials. Cognitive Psychology, 6, 159-171.

Erdelyi, M. H., Finkelstein, S., Herrell, N., Miller, B., \& Thomas, J. (1976). Coding modality vs. input modality in hypermnesia: Is a rose a rose a rose? Cognition, 4, 311-319.

ERdelyi, M. H., \& Kleinbard, J. (1978). Has Ebbinghaus decayed with time? The growth of recall (hypermnesia) over days. Journal of Experimental Psychology: Learning, Memory, \& Cognition, 4, 275-289.

Gillund, G., \& Shiffrin, R. M. (1984). A retrieval model for both recognition and recall. Psychological Review, 91, 1-67.

House, A. S., Williams, C. E., Hecker, M. H. L., \& KRyter, K. D. (1965). Articulation-testing methods: Consonantal differentiation with a closed-response set. Journal of the Acoustical Society of America, 37, 158-166.

HuNT, R. R., \& EINSTEIN, G. O. (1981). Relational and item-specific information in memory. Journal of Verbal Learning \& Verbal Behavior, 20, 497-514.

KINTsCH, W. (1970). Models for free recall and recognition. In D. A. Norman (Ed.), Models of human memory (pp. 331-373). New York: Academic Press.

Mensink, G. J., \& RaAijmakers, J. G. (1988). A model for interference and forgetting. Psychological Review, 95, 434-455.

Paivio, A. U. (1971). Imagery and verbal processes. New York: Holt, Rinehart \& Winston.

PAYNE, D. G. (1986). Hypermnesia for pictures and words: Testing the recall level hypothesis. Journal of Experimental Psychology: Learning, Memory, \& Cognition, 12, 16-29.

PAYNe, D. G. (1987). Hypermnesia and reminiscence in recall: A historical and empirical review. Psychological Bulletin, 101, 5-27. 
PAYNe, D. G. (1991). Selective auditory-visual interference effects in a dual-task paradigm: Implications for assessing individual differences. Proceedings of the Human Factors Society 35th Annual Meeting, 35, 622-626.

Payne, D. G., Hembrooke, H. A., \& Anastasi, J. S. (1993). Hypermnesia in free recall and cued recall. Memory \& Cognition, 21, 48 62.

Payne, D. G., Peters, L. J., Birkmire, D. P., \& Garinther, G. R. (1991). The effects of speech intelligibility level on concurrent visual task performance (Tech. Memorandum 17-91). U.S. Army Human Engineering Laboratory, Aberdeen Proving Ground MD.

RAaijmakers, J. G. W., \& Shiffrin, R. M. (1980). SAM: A theory of probabilistic search of associative memory. In G. H. Bower (Ed.) The psychology of learning and motivation: Advances in research and theory (Vol. 14, pp. 207-262). New York: Academic Press.

RoEdiger, H. L., III, \& Challis, B. H. (1989). Hypermnesia: Improvements in recall with repeated testing. In C. Izawa (Ed.), Current issues in cognitive processes: The Tulane Floweree Symposium on Cognition (pp. 175-199). Hillsdale, NJ: Erlbaum.

Roediger, H. L., III, Payne, D. G., Gillespie, G. L., \& Lean, D. S. (1982). Hypermnesia as determined by level of recall. Journal of Verbal Learning \& Verbal Behavior, 21, 635-655.

RoEDIGER, H. L., III, \& ThorPe, L. A. (1978). The role of recall time in producing hypermnesia. Memory \& Cognition, 6, 296-305.

ROEDIGER, H. L., III, \& WHEELER, M. M. A. (1993). Hypermnesia in episodic and semantic memory: Response to Bahrick and Hall. Psychological Science, 4, 207-208.

Shapiro, S. R., \& ERDELYI, M. H. (1974). Hypermnesia for pictures but not for words. Journal of Experimental Psychology, 103, 1218 1219.

Shaw, G. A., \& Bekerian, D. A. (1991). Hypermnesia for highimagery words: The effects of interpolated tasks. Memory \& Cognition, 19, 87-94.

SHEPARD, R. N. (1967). Recognition memory for words, sentences, and pictures. Journal of Verbal Learning \& Verbal Behavior, 6, 156-163.

SNODGRass, J. G., \& VANDERWART, M. (1980). A standardized set of
260 pictures: Norms for name agreement, image agreement, familiarity, and visual complexity. Journal of Experimental Psychology: Human Learning \& Memory, 6, 174-215.

Tulving, E., Schacter, D. L., \& Stark, H. A. (1982). Priming effects in word-fragment completion are independent of recognition memory. Journal of Experimental Psychology: Learning, Memory, \& Cognition, 8, 336-342.

WiCKENS, C. D. (1980). The structure of attentional resources. In P. S. Nickerson (Ed.), Attention and performance VIII (pp. 239-257). Hillsdale, NJ: Erlbaum.

WICKENs, C. D. (1984). Processing resources in attention. In R. Parasuraman \& R. Davies (Eds.), Varieties of attention (pp. 63-102). New York: Academic Press.

\section{NOTES}

1. Although the interference model of Mensink and Raaijmakers (1988) makes a number of precise predictions for temporally based interference effects, it has little to say about selective interference in the present experiments. Their model is based upon a stimulus-sampling approach, in which context is viewed as a set of dimensionless elements: What varies over time is the set of contextual elements that are active. The precise nature of these elements is not delineated, and, as a consequence, it is difficult to apply this model to the present experiments in which the study materials (Experiments 1-4), encoding instructions (Experiment 5), and interpolated activities were designed to require different cognitive processes.

2. These sentences were derived from a study (Payne, 1991; Payne, Peters, Birkmire, \& Garinther, 1991) in which we varied the speech intelligibility of the materials by manipulating aspects of the speech signal. For the materials used in the present experiment, subjects in our previous study were approximately $40 \%$ correct in recognizing the target word in a visual $6 \mathrm{AFC}$ recognition test.

(Manuscript received July 16, 1993; revision accepted for publication December 8, 1993.) 